CORRESPONDENCE

\section{Art and mental states: meaning requires dialogue}

Professor Green (2009) encourages us to think beyond the structured interview and symptom checklist and to allow our patients to express their experiences and distress in the ways, words and modalities most appropriate to them. This always has been and remains at the heart of our profession, even if prevailing ideologies encourage us to depart from it. However, pictures, more than words, rely for meaning not just on the originator but also on the perceiver - how a picture is perceived may bear little or no relationship to the thoughts and intent of its originator (Berger 1972). The same words or images can have radically different meaning or significance to different individuals or in different cultures. Sensitive exploration of meaning and an awareness of one's own cultural heritage and biases are essential parts of the use of art as a means of therapeutic communication.

Imbuing of mental state from the interpretation of a painting is fraught with danger. Green cites his own study (Cohen 2001) in support of his contention that abnormal mental states can be recognised from art, at least in children, although scarce detail is available from this conference abstract. There is little convincing evidence either from psychiatry (Rao 2006) or from art history (Dubuffet 1948) that it is possible to recognise individuals with mental illness by their art alone. Indeed Dubuffet, one of the fathers of 'art brut' or 'outsider art', writes: 'Our point of view is that art is the same in all cases, and there is no more an art of the mad than there is an art of the dyspeptic, or an art for those with bad knees' (Dubuffet 1948: p. 608). Art brut's emphasis was on encompassing the vitality and spontaneity of artists traditionally ignored or regarded as unschooled into the cathedra of the established art world and not on some intrinsic differentness that their art possessed.

Green writes: 'I am suggesting two processes: the first, a sustained sense of not knowing, linked with free-floating attention; the second, a gradual piecing together of local connections between elements of another's communication, which build up gradually into a more coherent overall image. This image is suddenly meaningful, "makes sense" and is accompanied by an intuition of the other person's mental state'(2009: p. 142). This has reflexive echoes of Hilton's writing in 1961 about the production of art: 'Painting is feeling. Just as much as a sentence describes, so a sequence of colours describes ... All art is an attempt to exteriorise one's sensations and feelings, to give them form ... Words and painting don't go together. The more words that are written about a painting the less people will see the painting.' (Hilton 2003 reprint: pp. 772-773).

Images are created through a process. In art therapy in particular it is the process and the relationship that develops between client, therapist and image and the shared understanding that develops from this that is of importance rather than an end product taken out of context and then layered with the viewer's own interpretations.

Berger J (1972) Ways of Seeing. Penguin.

Cohen S, Samson I, Shakespeare E, et al (2001) Forms of Feeling: An Analysis of Children's Drawings. Royal College of Psychiatrists' Annual Meeting, 2001: A Mind Odyssey. Conference abstract. Royal College of Psychiatrists

Dubuffet J (1948) Crude art preferred to cultural art. Reprinted (2003) in Art in Theory 1900-2000 (trans \& ed Harrison C, Wood P): 605-8. Blackwell.

Green J (2009) Form and mental state: an interpersonal approach to painting. Advances in Psychiatric Treatment, 15: 137-45.

Hilton R (1961) Remarks about painting. In Art in Theory 1900-2000 (eds Harrison C, Wood P): 771-3. Blackwell.

Rao A, Keshavan MS (2006) Images in psychiatry: can psychiatrists recognise mental illness in paintings? American Journal of Psychiatry, 163: 599 .

Andrew F. Clark Consultant Adolescent Psychiatrist, Greater Manchester West Mental Health NHS Foundation Trust, Prestwich Hospital, Bury New Road, Prestwich, Manchester, Greater Manchester M25 3BL, UK. Email: andrew.clark@gmw.nhs.uk; John Crossfield, Art Therapist, Young Persons Directorate, Greater Manchester West Mental Health NHS Foundation Trust doi: 10.1192/apt.15.5.398

The article (Rao 2006) that Clark \& Crossfield refer to in their e-Letter does not in fact justify their assumption that art does not indicate mental state. Rao \& Keshavan resorted to a chi-squared test to analyse their results, finding that untrained lay people were much less able than psychiatrists to infer mental illness in the tragic paintings of Gauguin, Van Gogh, Munch and Rothko. The article then concedes that psychiatrists are not so sure-footed when dealing with the ordinary works of individuals not found in museums.

Rao \& Keshavan's article belongs to a series in the American Journal of Psychiatry, 'Images in psychiatry', in which the overall implication is, in fact, that art does mirror the often turbulent mental state within. One article in the series introduces the American Visionary Art Museum in Baltimore, which shows the works of self-taught artists, many of whom have mental illnesses. The authors entitle their article 'Art as a portal into the minds of those with mental illness' (Fujimoto 2008). Another focuses on Caravaggio, with the grim painting of David holding, in place of the head of Goliath, Caravaggio's own severed head. The author comments that this reflects Caravaggio's 'insight 
into ... his psychopathology - pitilessly selfdestructive and ultimately fatal masochism' (Buckley 2008). Caravaggio was indeed a suicidal Goliath.

According to Dubuffet, all art requires instability, rather than moderation and reason, at its core. Art is the pursuit of the abnormal. Caravaggio - a homosexual, brawler and murderer hunted down by authority across Italy - was the typical artist as doomed rebellious outsider.

The association between art and mental illness is an old one. We could not cope without the insight of Clark \& Crossfield that art is a dialogue, but they are denying the history and essence of art in divorcing the mental state from what is depicted and displayed. Art seeks the heart of shadows that is in us all.

Buckley PJ (2008) Images in psychiatry: Caravaggio (1571-1610). American Journal of Psychiatry; 165: 201-2.

Fujimoto A, Douglas-Fujimoto M (2008) Images in psychiatry: art as a portal into the minds of those with mental illness. American Journal of Psychiatry, 165: 819

Rao A, Keshavan MS (2006) Images in psychiatry: can psychiatrists recognise mental illness in paintings? American Journal of Psychiatry, 163. 599 .

Zekria Ibrahimi Psychiatric Patient, Coombs Library, Uxbridge Road, Southall, Middlesex UB1 3EU, UK. Email: ibrahimizekria@ googlemail.com

doi: 10.1192/apt.15.5.398a

\section{Author's reply}

I am grateful for the responses to my article from Clark \& Crossfield and from Ibrahimi. In reply to both letters, I probably did not express myself clearly enough. I was not intending to re-express the old idea that there is any simple way in which one can infer an artist's 'mental state' from their painting. My article was intended to point to something rather different: that our aesthetic response to paintings occurs because we put ourselves into a relationship to them which is 'as if' the painting itself had a 'mental state'. This is not at all the same as suggesting that what one is looking at in a painting is simply a reflection of the artist's mental state. The painting has a life of its own which is often unpredictable. As both sets of correspondents point out, the meaning made from looking at the painting is as much up to the observer as to the artist.

I did say in the article that I did not suggest a simple correspondence of form and artists' mental state, particularly in the art of adults; there are too many factors of culture, style and history that affect the formal choices that an artist makes. Thus, there can be passionate emotion in Renaissance painting as well as in expressionism, and interpretation needs to take into account the stylistic conventions within which the artist is working. With young children the situation may be a little different just because their artistic productions are so much more spontaneous and cultural style has not yet a very big influence (children's drawings are pretty much the same around the world and through history). My research findings on the way that young children's formal expression reflects their mental state does therefore seem to hold in a slightly different way than for adults.

Jonathan Green Professor of Child and Adolescent Psychiatry, Psychiatry Research Group, Room 4.319, 4th Floor (east), University Place, Oxford Road, Manchester M13 9PL, UK. Email: jonathan.green@manchester.ac.uk

doi: 10.1192/apt.15.5.399

\section{Recovery without medication: choice, not moral superiority}

We feel that it is important to provide a response to the commentary by Dr Feeney (Feeney 2009) on our article in the May issue of Advances (Calton 2009) and to make our position absolutely clear. Given the many difficulties associated with use of antipsychotic medication (that Feeney himself readily accepts), we do believe that recovery with minimal or even no medication, where possible, is preferable. However, this does not mean that this is a 'morally superior' position, nor indeed, as Feeney implies, that people who take medication are somehow 'morally inferior'. Far from it. We are fully aware that medication is often necessary, given the context and preferences of the individual. Indeed, we have the utmost respect for people who make an informed decision to take medication and we refute absolutely the suggestion that we would feel otherwise. Dr Feeney should not confuse a personal view relating to the experience of taking powerful psychotropic medication ('chemical sanitation') with a moral imposition of these views on others. Our concern, however, is that people often take medication not from a position of informed choice, but because of coercion or a lack of alternatives.

We wonder whether Dr Feeney is being rather disingenuous when he claims that he (and the psychiatric profession as a whole) work holistically with people's 'informed choices', when he believes that the effectiveness of medication for treating psychosis is 'beyond dispute'. This 'holistic approach' to the treatment of psychosis appears to be predicated on the presumed necessity of medication. It is hard to see how Feeney and his colleagues do not impose this 'personal view' on 